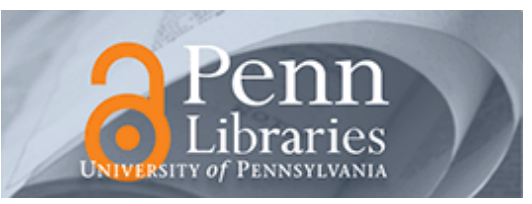

University of Pennsylvania

ScholarlyCommons

\title{
$5-2011$
}

\section{Safe Access to Safe Water in Low Income Countries: Water Fetching in Current Times}

\author{
Susan B. Sorenson \\ University of Pennsylvania, sorenson@sp2.upenn.edu \\ Christiaan Morssink \\ University of Pennsylvania, morssink@mail.med.upenn.edu \\ Paola Abril Campos \\ University of Pennsylvania
}

Follow this and additional works at: https://repository.upenn.edu/spp_papers

Part of the Demography, Population, and Ecology Commons, Gender and Sexuality Commons, Growth and Development Commons, Place and Environment Commons, Public Health Commons, and the Water Resource Management Commons

\section{Recommended Citation}

Sorenson, S. B., Morssink, C., \& Abril Campos, P. (2011). Safe Access to Safe Water in Low Income Countries: Water Fetching in Current Times. Retrieved from https://repository.upenn.edu/spp_papers/166

Sorenson, S. B., Morssink, C., \& Abril Campos, P. (2011). Safe access to safe water in low income countries: Water fetching in current times. Social Science \& Medicine, 72(9), 1522-1526. doi: 10.1016/j.socscimed.2011.03.010 NOTICE: This is the author's version of a work that was accepted for publication in Social Science \& Medicine. Changes resulting from the publishing process, such as peer review, editing, corrections, structural formatting, and other quality control mechanisms, may not be reflected in this document. Changes may have been made to this work since it was submitted for publication. A definitive version was subsequently published in Social Science \& Medicine, Volume 72, Issue 9, May 2011, 10.1016/j.socscimed.2011.03.010.

This paper is posted at ScholarlyCommons. https://repository.upenn.edu/spp_papers/166

For more information, please contact repository@pobox.upenn.edu. 


\title{
Safe Access to Safe Water in Low Income Countries: Water Fetching in Current Times
}

\begin{abstract}
A substantial portion of the world's population does not have ready access to safe water. Moreover, obtaining water may involve great expense of time and energy for those who have no water sources in or near home. From an historical perspective, with the invention of piped water, fetching water has only recently become largely irrelevant in many locales. In addition, in most instances, wells and clean surface water were so close by that fetching was not considered a problem. However, population growth, weather fluctuations and social upheavals have made the daily chore of carrying water highly problematic and a public health problem of great magnitude for many, especially women, in the poor regions and classes of the world. In this paper, we consider gender differences in water carrying and summarize data about water access and carrying from 44 countries that participated in the Multiple Indicator Cluster Survey (MICS) program. Women and children are the most common water carriers, and they spend considerable time (many trips take more than an hour) supplying water to their households. Time is but one measure of the cost of fetching water; caloric expenditures, particularly during droughts, and other measures that affect health and quality of life must be considered. The full costs of fetching water must be considered when measuring progress toward two Millennium Development Goals - increasing access to safe drinking water and seeking an end to poverty.
\end{abstract}

\section{Keywords}

economic development, gender, low-income countries, public health, sex differences, water, water carrying, women's health

\section{Disciplines}

Demography, Population, and Ecology | Gender and Sexuality | Growth and Development | Place and Environment | Public Health | Water Resource Management

\section{Comments}

Sorenson, S. B., Morssink, C., \& Abril Campos, P. (2011). Safe access to safe water in low income countries: Water fetching in current times. Social Science \& Medicine, 72(9), 1522-1526. doi: 10.1016/ j.socscimed.2011.03.010

NOTICE: This is the author's version of a work that was accepted for publication in Social Science \& Medicine. Changes resulting from the publishing process, such as peer review, editing, corrections, structural formatting, and other quality control mechanisms, may not be reflected in this document. Changes may have been made to this work since it was submitted for publication. A definitive version was subsequently published in Social Science \& Medicine, Volume 72, Issue 9, May 2011, 10.1016/ j.socscimed.2011.03.010. 
Safe access to safe water in low income countries: Water fetching in current times

\author{
Susan B. Sorenson, ${ }^{\mathrm{a}}$ Christiaan Morssink, ${ }^{\mathrm{b}}$ and Paola Abril Campos ${ }^{\mathrm{a}, \mathrm{c}}$ \\ ${ }^{a}$ School of Social Policy \& Practice, University of Pennsylvania \\ ${ }^{\mathrm{b}}$ School of Nursing, University of Pennsylvania, and the Philadelphia Global Water Initiative \\ ${ }^{\mathrm{c}}$ Public-Private Ventures
}

Corresponding author: Susan B. Sorenson, sorenson@sp2.upenn.edu

Keywords: Economic development, Gender, Low-income countries, Public Health, Sex differences, Water, Water carrying, Women's health

Acknowledgements: An earlier version of this paper was presented at the 2009 meeting of the American Public Health Association. 


\begin{abstract}
A substantial portion of the world's population does not have ready access to safe water. Moreover, obtaining water may involve great expense of time and energy for those who have no water sources in or near home. From an historical perspective, with the invention of piped water, fetching water has only recently become largely irrelevant in many locales. In addition, in most instances, wells and clean surface water were so close by that fetching was not considered a problem. However, population growth, weather fluctuations and social upheavals have made the daily chore of carrying water highly problematic and a public health problem of great magnitude for many, especially women, in the poor regions and classes of the world. In this paper, we consider gender differences in water carrying and summarize data about water access and carrying from 44 countries that participated in the Multiple Indicator Cluster Survey (MICS) program. Women and children are the most common water carriers, and they spend considerable time (many trips take more than an hour) supplying water to their households. Time is but one measure of the cost of fetching water; caloric expenditures, particularly during droughts, and other measures that affect health and quality of life must be considered. The full costs of fetching water must be considered when measuring progress toward two Millennium Development Goals - increasing access to safe drinking water and seeking an end to poverty.
\end{abstract}




\section{Background}

Almost thirty years after the United Nations proclaimed the 1980s to be the International DrinkingWater Supply and Sanitation Decade, more than one billion people still lack access to safe drinking water (Coles \& Wallace, 2005). Improved water sources are unavailable to a substantial percentage of the population in developing countries and elsewhere (for example, Indian reservations in the southwest United States). Essential for survival, water plays an important role in the establishment and organization of societies.

Human settlements such as towns and villages have long been constructed, in part, on the basis of access to water. Nomadic peoples, such as in Mongolia and the Arab peninsula, take multiple factors into account in their moves, including rain patterns and the availability of drinking water for animals and humans (e.g., Fernandez-Gimenez, 2000). Agricultural practices are predicated on techniques that guarantee a water supply. And, the availability of surface and ground water are among the conditions taken into consideration when villages and other human settlements are established. In all, there was and continues to be a balancing act between humans and nature around the availability of fresh water.

The world's population has increased dramatically in the last century, and there is better and more widely available technology to pipe water directly to population centers. Many watersheds on the planet have reached a tipping point. Although the amount of water on the earth is constant, the amount of available fresh water is actually shrinking (Gleick, 1998) and the demand for water is increasing (Rogers, 2000).

When on-site water supply is not of sufficient quality and quantity or when the price of water delivery by merchants is too high, one or more members of a household or community must take time and energy to obtain it. A cursory review of (non-scientific) literature, poetry and 
paintings indicates that fetching water has been a task for women, children and, when and where possible, slaves or servants, and that the activity was romanticized (for example, images of a serene and beautiful woman balancing a water pot on her head). Little research has quantified the burden of this work on women, who bear the primary responsibility to identify appropriate containers, carry them to the water source, sometimes over great distance and difficult terrain, obtain the water, and return home with the heavy, shifting loads. Only recently, under pressure from such groups as Women For Water Partnership, has gender-specific analysis of water-related policy issues been given attention.

Water fetching has a complex place in the social life of communities, and we attempt herein to identify key considerations, including relative burden, so as to allow for a more subtle understanding of population differences in water carrying. Multiple demographic characteristics likely enter in (for example, gender, class, caste, and race); we focus herein on gender, which, across time and locale, appears to be an important consideration in water fetching.

\section{Current estimates of water fetching by gender}

UNICEF, in conjunction with local governments, began the Multiple Indicator Cluster Survey (MICS) program in 1995 to collect data by which to monitor the situation of children and women in developing countries. Questionnaires were developed in consultation with other UN organizations, interagency groups monitoring the Millennium Development Goals, interagency development groups, and the USAID-supported Demographic Health Surveys. The collaborative approach helped ensure comparability across surveys (for example, across countries and languages).

In each country, a two-stage, stratified cluster sample was drawn to provide estimates of social indicators at the national, regional, and urban-rural levels. Although often conducted in less than optimal conditions, the quality of the MICS data is considered to be high. Sample sizes were 
large (often in the tens of thousands), extensive training and supervision of the interviewers occurred, and response rates routinely were above $90 \%$. Population weights were applied to the data to account for non-response. In-person interviews have been conducted in about 100 countries. Many countries included a survey section on water supply and sanitation as part of the household questionnaire, thus, the resulting data help elucidate water accessibility and use in the developing world.

Reports published in English, Spanish, and French were accessed electronically via the UNICEF website (Monitoring the Situation of Children and Women, n.d.) and information was abstracted about the main source of drinking water for members of the household. If the drinking water source was not on premises, participants were asked how long it takes "to go there, get the water, and come back" and asked who usually goes to the source to fetch water for the household (with probes about gender of the carrier and whether the fetcher is less than 15 years old). Table 1 presents MICS data on water carrying from 44 developing countries.

Insert Table 1 about here

Women are the most common water carriers around the world, and they spend considerable time supplying water to their households, depending on household size, distance, seasons, and other variables such as household income. In the 44 countries, on average, women are the most common water fetchers followed by men and children ( $58.6 \%$ vs. $30.4 \%$ and $9.1 \%$, respectively). There is a direct positive association between not having access to an improved water source and the percent of water fetchers who were women ( $\mathrm{r}=.35)$; a higher association was noted between not having improved water on premises and the percent of water fetchers who were women ( $r=.43)$. 
In the countries where half or fewer of the households have access to an improved water source, women are the most common water carriers. For example, $66.4 \%$ of the water carriers are women for the $71 \%$ of households in Somalia that lack access to an improved water source. In Laos, women are $83.4 \%$ of the water carriers for the $48.5 \%$ of households that lack access to water; in Nigeria, those figures are $46.6 \%$ and $51.9 \%$, in Sierra Leone, they are $69.8 \%$ and $53 \%$, and in Mauritania, they are $70.5 \%$ and $49.5 \%$.

The mean time to fetch water varies greatly, and gender differences are noted in the time spent fetching. In Mauritania, Somalia and Yemen, at the high end, where fewer than half of the households have an improved water source on premises, the average trip takes over an hour, and two of every three water carriers are women. It appears that, as the percentage of households with an improved water source on-site increases, there is less uniformity in whether the most common fetcher was a woman, man, or child, implying that as the societal burden of fetching becomes less, men and children participate more. If an improved water source is not on-premises, the association between the mean time to fetch the water and the percent of water carriers who are men is -.27. The correlation between the percent of water carrying that took more than 15 minutes and the percentage of water carriers who are men is -.66; if the carrier is a woman, the association is .41, suggesting that the longer the time spent, the lower the likelihood that men are the water carriers.

Thus, in these 44 countries, women are the likely water fetchers and the time they invest in this activity each day is substantial, nearly an hour per trip.

\section{Perspectives on women and water}

In recent years, two main perspectives - health and economic - have dominated research on women's work in supplying water. Social networking and political participatory aspects of women in relation to water have garnered substantially less attention. 
Water-borne diseases are common in developing countries, and the health perspective focuses largely on the consequences of using contaminated water for drinking and sanitation (World Health Organization and United Nations Children's Fund Joint Monitoring Programme for Water Supply and Sanitation, 2008). Although the centrality of women in ensuring the health of the family is widely acknowledged, little research addresses the specific, and negative, health aspects associated with collecting water. Long-term back injuries, micronutrient deficiencies due to high caloric expenditure during food scarcity periods, or negative impacts on the health status of young children are mentioned rarely and often only as a secondary adverse effect. The water fetchers are almost secondary to the water itself.

By contrast, the economic perspective focuses primarily on the water fetchers and their lack of agency. The opportunity cost argument has drawn the attention of policy makers concerned about economic growth and how women can be turned into economic agents. Research from an opportunity cost perspective notes the time spent fetching water and assumes that, if freed from this chore, women will devote their time to income-generating activities and augment household incomes. Although it is an effort to place a value on women's unpaid work, key assumptions are based on little evidence - having time does not necessarily translate into having access to incomegenerating activities - and are concerned primarily with economic growth rather than women's health status or quality of life.

Social aspects of fetching water (e.g., networking, social support, quarrels, social denigration) are discussed sporadically and often anecdotally in the literature. Women's role in protecting and improving the environment and how it is influenced by the need to fetch water is an emerging strand of research, facilitated by the work of Nobel prize winner and founder of the Green Belt Movement Wangari Maathai, environmental activist Vandana Shiva, and others. 


\section{Measuring water fetching and its effects}

Water fetching reflects a social and health disparity of major proportion. Average daily per capita domestic water consumption ranges from 1 gallon in Mozambique and 4 gallons in Angola, Cambodia, Ethiopia, Haiti, Rwanda and Uganda to 150 gallons in the United States (Data360, n.d.; 2002 data). In recent years, there have been several approaches to measuring water fetching, none of them comprehensive. The next sections describe several constructs that may more fully capture the individual and societal burdens of fetching water.

Linear distance to the improved water source was the first quantified measure. UNICEF defines access to an improved water source as having an improved water source within $1 \mathrm{~km}$ of the dwelling (World Health Organization, 2000). The Joint Monitoring Program (JMP) on Water and Sanitation definition adds water quality and quantity (World Health Organization and United Nations Children’s Fund Joint Monitoring Programme for Water Supply and Sanitation, 2008). According to JMP, to provide for the minimal daily needs of one person, the water fetcher would carry a container for 0.62 miles, obtain about 5 gallons of water, and walk back 0.62 miles bearing roughly 44 pounds of water. The JMP definition is used widely in policy papers published by international organizations.

Time spent may be a better indicator of the burden of fetching water in some locales. In densely populated areas, improved water sources might be nearby but waiting in line can take an hour or more (Ray, 2007). Women's workload in agricultural societies often exceeds that of men (Mpetsheni, 2001), and collecting water and heating fuel are two of the most time-consuming activities. Moreover, women spend more time on household work when the water infrastructure is inadequate.

Caloric expenditure is a step toward focusing on health. Many women in developing 
countries suffer from malnutrition and iron deficiency, and the energy consumed in fetching water, particularly during periods of scarcity (Buor, 2004), is consequential in that it worsens their condition. Health risks extend to children when the water carriers are pregnant or nursing. In addition, during droughts, multiple trips must be made each day to obtain sufficient water for the household, thereby increasing caloric expenditures at a time when health is likely already compromised.

Opportunity cost, useful in economic arguments, considers what women would do with their time if they did not spend it collecting water. For girls and young women the opportunity cost is attending school; for adult women it is participating in income-generating activities.

\section{Neglected concerns}

Future research on water fetching will be strengthened by considering largely ignored factors, ones that go beyond time, linear distance, caloric expenditures, and opportunity costs.

Road casualties are an important risk. Transportation infrastructure is poor in developing countries, especially in rural areas. Water fetching often involves walking on poorly designed and chaotic roadways (often the only place to walk), and pedestrians share the roadways with vehicles and cyclists. Injuries and death can result: over $90 \%$ of the world's roadway fatalities occur in lowand middle-income countries, and a substantial portion are pedestrians and other vulnerable road users (World Health Organization, 2009).

Assault and attack risks are not well documented. Women walking some distance alone or in small groups can be targets of attacks by humans and wild animals. For example, almost all rape victims in Eastern Congo described being attacked when fetching water or wood or doing laundry away from the household (Kircher, 2007). In addition, women sometimes face abusive treatment when they need to fetch water from private wells on the land of wealthier farmers (Shah, 2002). 
Related health outcomes vary widely. The spread of diseases from worms (Steinmann, Keiser, Box, Tanner, \& Utzinger, 2006) and bacteria (An old enemy returns, 2009) is facilitated by human and animal traffic around water sources. Injuries to the back, neck, or other joints while carrying water are treated as a collateral or isolated event. Personal appearance (e.g., hair loss from carrying containers on the head [Bimla, Dilbaghi, \& Raina, 2003]) can be affected, too.

The number of trips, which varies during and across seasons, is needed to calculate time and caloric expenditures. One ergonomic study in Haryana, India found that women fetched and carried on the head, on average, 23 vessels of water each day during the summer (17 in the morning and 6 in the evening) (Bimla et al., 2003). The weight of the vessel and the drudgery of water carrying, which can be considerable particularly with multiple trips, also merit investigation.

The condition of the terrain can require sustained vigilance. For example, when carrying water over very uneven, steep hillsides (a common condition in Guatemala and elsewhere), falling is always a risk. Where there is a road, water fetchers will use it despite being at risk from vehicles. Post-disaster (landslide, tsunami, earthquake, etc.) areas pose numerous challenges to water fetchers whether they are walking or cycling.

Priorities in water use may be important. Drinking and cooking are the first priorities in domestic water use; water consumption for personal hygiene (for example, hand washing) and sanitation is likely to be sacrificed when the supply is low. Status within the household can affect allocation; for example, in a qualitative study in Ghana, women reported that when water is scarce men have priority for bath water (Avotri \& Walters, 1999). Women's health as well as dignity and sense of personal worth can be affected by their experiences while collecting water and, particularly sanitation-related diseases and illnesses, by the within-household allocation of water itself. 


\section{Implications for research}

Research on the multiple impacts of fetching water on women's lives is incomplete, and the lack of gender-disaggregated data - as well as data on related health risks - obscures a more complete understanding of the unequal burden (Ray, 2007). Attendees at a recent Expert Group Meeting organized by the UN-Water Decade Programme on Capacity Development stressed the need for gender-disaggregated data (Seager, 2008). Data from the MICS program are a step forward. Such efforts extend initial public health concerns about water quality and quantity to health and social considerations related to the water fetchers.

Our understanding of water carrying can be facilitated by research that measures water fetching in multiple ways. As noted above, water fetching can be measured in time, distance, caloric expenditure, and opportunity costs but, to our knowledge, all of these aspects have not been assessed simultaneously. Including variables such as the weight of the vessel, condition of the terrain, and drudgery of the work (for example, the number of trips) would provide greater awareness of the task. In addition, the risk of road casualties, assaults and attacks, and related health concerns (for example, neck and back injuries) could be estimated in future research. Such investigations would result in a more complete assessment of the costs of water fetching and a better sense of the fetchers' experience of the work itself.

MICS data provide useful estimates of the time spent fetching water and the differential by gender. Future research could be expanded to explore the role of additional demographic characteristics (class, caste, race, and ethnicity among others such as age and [dis]ability), geographic or other differences in water carrying. Likewise, the interpersonal aspects of fetching water (for example, networking, social support, quarrels, and social denigration) merit further research. Understanding the interplay of multiple factors in how the task of water fetching is 
assigned and assumed will provide a more thorough understanding of how communities meet their needs for water.

Priorities in the allocation of water seem to merit additional investigation for at least two reasons, namely, sanitation-related health problems and societal roles. Sanitation can be a distant second priority to consumption, especially in areas where water is scarce and it takes several hours to fetch a pot of water. Assumptions and expectations about the within-household allocation of water can reduce women's access to water for sanitation (for example, during menstruation, pregnancy, and childbirth) as well as basic practices such as hand washing. In addition, gender roles result in women assuming responsibility for the sanitation activities and care of children, elderly, and the household in general. When water is limited, sanitation-related illnesses can be more common and, in turn, bring about debt and poverty. As noted elsewhere, there is a tight intertwining of women's health, labor, poverty and harsh environmental conditions (Wong, Li, Burris, \& Yang, 1995).

Women's lack of political representation in many countries in the developing world may be a major obstacle to bringing water infrastructure to the forefront of public expenditure. In India, the gender of the local chief is associated with the allocation of public goods; investment in drinking water and in roads is higher when women are chiefs (Chattopadhyay \& Duflo, 2004). Political representation is but one component of women's participation in civic life. In many locales, greater participation of women in planning and decision making may benefit the health of the community but threaten established roles and structures. Once such example is the privitization of water - the water supply is transformed from a public good into a private good by which costs can be incurred and profits generated - which, although not new, has occurred on a broader scale in developing countries in recent years. Research may shed light on the association between women's engagement 
and participation in the multiple levels of decision making and the accessibility of sufficient fresh water.

\section{Conclusion}

Water for domestic and agricultural use is indispensable for food security and public health. As climate change, population growth, and development affect water availability, internal as well as external cooperative efforts are essential (Barnaby, 2009; Gleick, 2000). Policies designed to improve infrastructure are needed to increase, not just access to water but, safe access to safe and reliable water or risk losing the health advantage of having a nearby water source (Caldwell, Caldwell, Mitra, \& Smith, 2003; Hunter, Zmirou-Navier, \& Hartemann, 2009). Doing so will increase the health of all and the health, safety, education and income of women, the primary suppliers of water to households around the globe. 


\section{References}

An old enemy returns. (2009). Bulletin of the World Health Organization, 87, 85-86.

Avotri. J., \& Walters, V. (1999). 'Just look at our work and see if you have any freedom on earth': Ghanaian women’s accounts of their work and their health. Social Science \& Medicine, 48, 11231133.

Barnaby, W. (2009). Do nations go to war over water? Nature, 458, 282-283.

Bimla, G.S., Dilbaghi, M., \& Raina, K. (2003). Rural women carry the load of fetching water. Indian Journal of Social Work, 64, 65-75.

Buor, D. (2004). Water needs and women's health in the Kumasi metropolitan area, Ghana. Health \& Place, 10, 85-103.

Caldwell, B.K., Caldwell, J.C., Mitra, S.N., Smith, W. (2003). Searching for an optimum solution to the Bangladesh arsenic crisis. Social Science \& Medicine, 45, 2089-2096.

Chattopadhyay, R., \& Duflo, E. (2004). Women as policy makers: evidence from a randomized policy experiment in India. Econometrica, 72, 1409-1443.

Coles, A., \& Wallace, T. (Eds.) (2005). Gender, water and development. New York: Berg.

Data 360. (n.d.). Average water use per person per day. (data from 2002).

http://www.data360.org/dsg.aspx?Data_Set_Group_Id=757 (Accessed 12 August 2010).

Fernandez-Gimenez, M.E. (2000). The role of Mongolian nomadic pastoralists' ecological knowledge in rangeland management. Ecological Applications, 10, 1318-1326.

Gleick, P.H. (1998). Water in crisis: Paths to sustainable water use. Ecological Applications, 8, 571579.

Gleick, P.H. (2000). The changing water paradigm: Look at twenty-first century water resources development. Water International, 25, 127-138.

Hunter, P. R., Zmirou-Navier, D., \& Hartemann, P. (2009). Estimating the impact on health of poor reliability of drinking water interventions in developing countries. Science of the Total Environment, 407, 2621-2624.

Kircher, S. (6 August 2007). Hell on earth - Systematic rape in Eastern Congo. Journal of Humanitarian Assistance. http://jha.ac/2007/08/06/hell-on-earth-systematic-rape-in-eastern-congo/ (accessed 30 June 2010).

Mpetsheni, Y. (2001). Putting a value to women’s work. Agenda, 47, 60-64. 
Monitoring the Situation of Children and Women. (n.d.). UNICEF. http://www.childinfo.org/mics3_surveys.html. (accessed 15 August 2009).

Ray, I. (2007). Women, water and development. Annual Review of Environment and Resources, 32, 421-449.

Rogers, P. (2000). Water resources in the twentieth and one half century: 1950-2050. Water Resources Update, 116, 62-66.

Seager, J. (ed.). (2008). Expert group meeting: Gender-disaggregated data on water and sanitation, United Nations Headquarters, New York. UNW-DPC Publication Series.

http://www.womenforwater.org/docs/UNW-DPC_KnowledgeReportNo.1.pdf (accessed 8 September 2009).

Shah, A. (2002). Women, water, irrigation: respecting women's priorities. Economic and Political Weekly, 37, 4413-4420.

Steinmann, P., Keiser, J., Bos, R., Tanner, M., \& Utzinger, J. (2006). Schistosomiasis and water resources development: systematic review, meta-analysis, and estimates of people at risk. The Lancet Infectious Diseases, 6, 411-425.

Wong, G.C., Li, V.C., Burris, M.A., \& Xiang, Y. (1995). Seeking women's voices: setting the context for women's health interventions in two rural counties in Yunnan, China. Social Science \& Medicine, 41, 1147-1157.

World Health Organization. (n.d.). Global water supply and sanitation assessment 2000. http://www.who.int/water_sanitation_health/monitoring/globalassess/en/ (accessed 5 September 2009).

World Health Organization. (2009). Global status report on road safety.

http://www.who.int/violence_injury_prevention/road_safety_status/2009/en/ (accessed 3 September 2009).

World Health Organization and United Nations Children's Fund Joint Monitoring Programme for Water Supply and Sanitation (JMP). (2008). Progress on drinking water and sanitation: special focus on sanitation. UNICEF, New York and WHO, Geneva.

http://www.childinfo.org/mdg/mdg_assessmentreport_08.pdf (accessed 3 October 2009). 
Table 1. Water accessibility, time to water source, and carriers in the Multiple Indicator Cluster Surveys (MICS-3), by region, \%

\begin{tabular}{|c|c|c|c|c|c|c|c|c|c|c|}
\hline \multirow[b]{2}{*}{ Country } & \multicolumn{2}{|c|}{ Access to Water } & \multicolumn{5}{|c|}{$\begin{array}{c}\text { Time to Water Source }^{\mathrm{a}} \\
\text { in Minutes }\end{array}$} & \multicolumn{3}{|c|}{ Water Carriers ${ }^{\mathrm{b}}$} \\
\hline & $\begin{array}{l}\text { water } \\
\text { source }\end{array}$ & $\begin{array}{l}\text { Water on } \\
\text { premises }\end{array}$ & Mean & $<15$ & $15-30$ & $30-60$ & $60+$ & Women & Men & Children \\
\hline \multicolumn{11}{|c|}{ Central and Eastern Europe and Commonwealth of Independent States } \\
\hline Albania & 97.5 & 86.6 & 17.7 & 8.8 & 1.6 & 1.6 & 1.4 & 67.2 & 28.9 & 3.8 \\
\hline Belarus & 99.6 & 80.8 & 7.7 & 16.8 & 2.4 & 0.0 & 0.0 & 50.3 & $48.6^{\mathrm{c}}$ & 0.0 \\
\hline Bosnia and Herzegovina & 98.7 & 88.8 & 12.1 & 7.6 & 2.5 & 0.8 & 0.3 & 51.0 & 46.7 & 1.5 \\
\hline Georgia & 94.2 & 78.9 & 16.3 & 11.7 & 5.6 & 2.8 & 0.9 & 61.8 & 35.7 & 1.6 \\
\hline Kazakhstan & 93.7 & 73.4 & 19.0 & 11.2 & 9.1 & 4.7 & 1.4 & 29.9 & 64.6 & 5.5 \\
\hline Kyrgyzstan & 88.2 & 58.0 & 16.0 & 23.9 & 10.9 & 4.8 & 1.7 & 49.3 & 28.7 & 19.2 \\
\hline Macedonia & 99.0 & 96.0 & 19.0 & 2.2 & 0.3 & 0.6 & 0.5 & 62.7 & 32.4 & 0.1 \\
\hline Montenegro & 98.3 & 95.7 & 15.1 & 2.7 & 0.7 & 0.7 & 0.1 & 61.7 & 29.8 & 8.5 \\
\hline Serbia & 98.9 & 95.5 & 22.3 & 2.0 & 1.0 & 0.6 & 0.5 & 40.7 & 52.7 & 1.3 \\
\hline Tajikistan & 69.5 & 45.1 & 26.0 & 24.8 & 12.9 & 8.2 & 8.3 & 79.1 & 9.5 & 11.2 \\
\hline Ukraine & 97.8 & 73.0 & 10.2 & 22.6 & 2.9 & 1.1 & 0.3 & 47.7 & 51.7 & 0.7 \\
\hline Uzbekistan & 89.6 & 59.5 & 14.8 & 19.6 & 13.8 & 6.8 & 0.0 & 58.3 & 35.7 & 5.6 \\
\hline \multicolumn{11}{|l|}{ East Asia and the Pacific } \\
\hline Laos & 51.5 & 37.4 & 11.7 & 44.9 & 10.8 & 5.1 & 1.7 & 83.4 & 8.3 & 7.8 \\
\hline Mongolia & 71.6 & 21.8 & 30.7 & 26.8 & 20.7 & 19.8 & 10.8 & 31.8 & 48.8 & 19.3 \\
\hline Thailand & 94.0 & 91.5 & 10.6 & 6.6 & 0.6 & 0.5 & 0.4 & 61.4 & 32.0 & 5.0 \\
\hline Vanuatau & 85.0 & 48.7 & 13.6 & 36.0 & 8.5 & 3.5 & 2.0 & 59.3 & 30.0 & 7.9 \\
\hline Viet Nam & 89.0 & 89.9 & 15.7 & 5.7 & 2.5 & 0.9 & 0.3 & 58.7 & 30.5 & 4.6 \\
\hline \multicolumn{11}{|c|}{ Eastern and Southern Africa } \\
\hline Burundi & 64.3 & 3.6 & 36.6 & 20.5 & 21.8 & 29.1 & 23.6 & 64.7 & 8.8 & 39.4 \\
\hline Malawi & 75.0 & 6.0 & 37.1 & 25.2 & 23.0 & 25.3 & 20.3 & 87.2 & 5.8 & 6.9 \\
\hline Somalia & 29.0 & 14.9 & 70.2 & 14.7 & 14.7 & 20.6 & 31.6 & 66.4 & 26.1 & 6.5 \\
\hline \multicolumn{11}{|c|}{ Middle East and North Africa } \\
\hline Djibouti & 93.5 & 83.3 & 34.6 & 3.3 & 2.9 & 4.4 & 4.2 & 79.4 & 10.3 & 10.2 \\
\hline
\end{tabular}




\begin{tabular}{|c|c|c|c|c|c|c|c|c|c|c|}
\hline Iraq & 79.1 & 79.1 & 21.1 & 9.2 & 7.5 & 2.1 & 1.7 & 55.1 & 37.1 & 6.7 \\
\hline Palestinians in Lebanon & 91.2 & 65.7 & 29.8 & 5.8 & 3.2 & 3.1 & 0.1 & 19.2 & 75.4 & 5.2 \\
\hline Syrian Arab Republic & 88.3 & 86.6 & 19.6 & 8.7 & 1.0 & 0.9 & 1.4 & 22.4 & 73.9 & 1.6 \\
\hline Yemen & 59.0 & 49.3 & 63.7 & 6.8 & 6.2 & 10.0 & 26.8 & 68.2 & 11.4 & 15.9 \\
\hline \multicolumn{11}{|l|}{ South Asia } \\
\hline Bangladesh & 97.6 & 68.0 & 12.2 & 22.6 & 5.9 & 2.7 & 0.5 & 88.8 & 4.7 & 5.6 \\
\hline \multicolumn{11}{|c|}{ Latin America and the Caribbean } \\
\hline Belize & 96.5 & 77.3 & 10.2 & 15.4 & 3.2 & 1.0 & 0.6 & 46.2 & 41.6 & 5.0 \\
\hline Cuba & 91.6 & 81.2 & 16.5 & 10.1 & 4.4 & 2.2 & 0.8 & 31.5 & 67.9 & 0.3 \\
\hline Guyana & 91.2 & 86.1 & 19.9 & 7.0 & 2.8 & 1.5 & 1.0 & 33.5 & 43.2 & 10.4 \\
\hline Jamaica & 94 & 84.9 & 20.4 & 6.3 & 4.7 & 2.9 & 0.8 & 32.2 & 56.5 & 7.6 \\
\hline Suriname & 91.7 & 85.4 & 19.7 & 6.4 & 2.7 & 2.8 & 1.0 & 65.0 & 23.5 & 2.9 \\
\hline Trinidad and Tobago & 96.4 & 92.9 & 18.5 & 3.2 & 1.8 & 0.8 & 0.4 & 20.8 & 71.1 & 2.7 \\
\hline \multicolumn{11}{|l|}{ West and Central Africa } \\
\hline Burkina Faso & 77.3 & 10.9 & 35.7 & 18.2 & 22.6 & 28.0 & 18.3 & 85.0 & 7.7 & 6.3 \\
\hline Cameroon & 69.3 & 20.2 & 26.1 & 28.7 & 20.7 & 20.1 & 9.5 & 45.8 & 25.5 & 28.2 \\
\hline Central African Republic & 64.0 & 5.4 & 26.0 & 30.8 & 25.5 & 26.1 & 10.7 & 73.6 & 10.9 & 14.9 \\
\hline Cote d'Ivoire & 76.0 & 55.2 & 27.3 & 16.6 & 10.5 & 10.5 & 6.2 & 85.9 & 3.9 & 9.6 \\
\hline Gambia & 85.1 & 32.9 & 20.6 & 27.6 & 19.3 & 14.4 & 4.4 & 82.0 & 7.3 & 8.6 \\
\hline Ghana & 78.1 & 16.2 & 18.4 & 45.3 & 20.0 & 13.0 & 5.3 & $64.4^{\mathrm{d}}$ & $17.3^{\mathrm{e}}$ & 15.6 \\
\hline Guinea-Bissau & 59.9 & 22.4 & 21.3 & 34.2 & 20.0 & 13.3 & 5.5 & 93.1 & 1.3 & 5.0 \\
\hline Mauritania & 50.5 & 48.6 & 67.0 & 7.0 & 6.7 & 11.4 & 24.3 & 70.5 & 18.1 & 9.3 \\
\hline Nigeria & 49.1 & 17.1 & 29.9 & 28.7 & 19.8 & 21.1 & 11.2 & 46.6 & 34.5 & 18.5 \\
\hline Sao Tome and Principe & 86.2 & 25.8 & 16.2 & 43.2 & 15.8 & 10.0 & 3.6 & 66.8 & 19.5 & 13.5 \\
\hline Sierra Leone & 47.0 & 8.8 & 17.2 & 48.5 & 21.0 & 17.6 & 3.7 & 69.8 & 8.7 & 21.2 \\
\hline Togo & 60.6 & 18.1 & 23.6 & 35.6 & 21.5 & 16.1 & 8.3 & 58.1 & 11.3 & $17.0^{\mathrm{f}}$ \\
\hline
\end{tabular}

${ }^{a}$ Measured by the following survey question: "How long does it take to go there, get water, and come back?"

b When the columns do not sum to 100.0, the remaining categories were a combination of missing, "don't know" or other.

${ }^{\mathrm{c}}$ The $48.6 \%$ includes adult men and boys under the age of 15 .

$\mathrm{d}$ The $64.4 \%$ consists of women (42.2\%) and women and children (22.2\%).

${ }^{\mathrm{e}}$ The $17.3 \%$ consists of men (15.9\%) and men and children (1.4\%).

f An additional 5.7\% said "men, women, and children." 
Note. Data are from the Multiple Indicator Cluster Surveys (http://www.childinfo.org/mics3_surveys.html). Data were abstracted from reports that were posted online in four languages. Several countries were not included: the section on water and sanitation was not included in surveys in Tunisia and Palestinians in the Syrian Arab Republic; water access was, but time and carrier were not, asked about in Algeria; access to the Turkmenistan report was restricted; and, at the time these data were compiled (January 15, 2011), reports were not available for Kenya, Lebanon, and Mozambique. 